\title{
The Reaction with Oxygen of Cytochrome Oxidase (Cytochrome $d$ ) in Escherichia coli K12: Optical Studies of Intermediate Species and Cytochrome $b$ Oxidation at Sub-zero Temperatures
}

\author{
By ROBERT K. POOLE, ${ }^{1 *}$ IAN SALMON ${ }^{1} \dagger$ AND BRITTON CHANCE 2 \\ ${ }^{1}$ Department of Microbiology, Queen Elizabeth College (University of London), Campden Hill, \\ London $W 87 A H, U . K$. \\ 2 Johnson Research Foundation, Department of Biochemistry and Biophysics, University of \\ Pennsylvania, Philadelphia, Pennsylvania 19104, U.S.A.
}

(Received 22 September 1982)

\begin{abstract}
Optical changes in $d$ - and $b$-type cytochromes, following initiation of the reaction of cytochrome oxidase $d$ with $\mathrm{O}_{2}$, have been studied in cells and derived membrane particles from oxygenlimited cultures of Escherichia coli $\mathrm{K} 12$. At successively higher temperatures between -132 and $-88^{\circ} \mathrm{C}$, the first scan after photolysis of the $\mathrm{CO}$-liganded, reduced oxidase in the presence of $\mathrm{O}_{2}$ shows a diminution of cytochrome $d_{650}$ (believed to be an early intermediate in the $\mathrm{O}_{2}$ reaction) and a slow increase in absorbance at 675 to $680 \mathrm{~nm}$ due to an unidentified chromophore. A similar sequence occurs when a single sample is scanned repetitively at $-91{ }^{\circ} \mathrm{C}$. At higher temperatures, oxidation of at least two spectrally distinct cytochromes $b$ occurs. Selective photolysis of the cytochrome $d-\mathrm{CO}$ complex with a $\mathrm{He}-\mathrm{Ne}$ laser shows that neither of these cytochromes is the CO-binding cytochrome $o_{436}$. In all oxidation states examined, no absorbance in the 720 to $860 \mathrm{~nm}$ region was observed; it is concluded that both cytochromes $d$ and $o_{436}$ lack redox-active copper that has an environment similar to the copper(s) in mitochondrial cytochrome $c$ oxidase.

The amount of cytochrome $d_{650}$ (but not the amount of reduced cytochrome $o_{436}$ ) formed after photolysis is directly proportional to the oxygen concentration in the sample at the time of freeze trapping. The results are discussed in relation to the composition and mechanism of action of cytochrome $d$.
\end{abstract}

\section{INTRODUCTION}

An unusual pigment with an absorption band well within the red region of the spectrum (at about $630 \mathrm{~nm}$ ) was first observed in Escherichia coli and Shigella dysenteriae (Yaoi \& Tamiya, 1928). The component, designated cytochrome $a_{2}$ (Keilin, 1933), was shown by several workers to be widespread among bacteria, autooxidizable, and capable of combining with $\mathrm{CO}$ and cyanide (for a review, see Lemberg \& Barrett, 1973). Following the discovery that the prosthetic group is an iron-chlorin (Barrett, 1956), the enzyme was subsequently reclassified as cytochrome d.

Castor \& Chance (1959) obtained photo-action spectra for the relief of CO inhibition in several bacteria and demonstrated the role of cytochrome $d$ as an oxidase. More recently, Hoffman et al. (1980) have demonstrated the same function for cytochrome $d$ in Azotobacter vinelandii. In E. coli and other bacteria, this oxidase is formed when the availability or utilization of oxygen is restricted (for references, see Poole \& Chance, 1981), a finding consistent with the high $\left(K_{\mathrm{m}}=0.025 \mu \mathrm{M}\right) \mathrm{O}_{2}$ affinity of the E. coli enzyme (Rice \& Hempfling, 1978). This value may be lower than the $K_{\mathrm{m}}$ for $\mathrm{O}_{2}$ of cytochrome $a a_{3}$ (Jones, 1978; Poole et al., 1979a).

+ Present address: Biological Laboratory, The University, Canterbury, Kent CT2 7NJ, U.K. 
The mechanisms by which cytochrome oxidases reduce oxygen (dioxygen) are currently receiving much attention. The mode of action of the mitochondrial cytochrome $c$ oxidase (EC 1.9.3.1) has been most extensively studied (Chance, 1981; Wikström et al., 1981). However, the diversity of structures exhibited by bacterial oxidases, having the same function as the mitochondrial enzyme, offers the opportunity for identifying the essential features of oxidase action in a comparative study. The redox-active metal centres in cytochrome $c$ oxidase are two irons in haems $a$ and $a_{3}$ and two coppers. In the reaction with $\mathrm{O}_{2}$, the reactive centre consists of the coupled metal ion pair, cytochrome $a_{3}$ and the 'EPR invisible' $\mathrm{Cu}_{a_{3}}$ or $\mathrm{Cu}_{\mathrm{B}}$. However, with the exception of the structurally-simple $a a_{3}$-type oxidases recently identified in bacteria (Ludwig, 1980), there is little convincing evidence for the involvement of copper in bacterial cytochrome oxidases. In these systems, mechanisms for oxygen reduction must be sought that involve electron donation only from haems. The best-characterized bacterial oxidases are the cytochrome $o$ of the myxobacterium Vitreoscilla and the cytochrome $c d_{1}$ oxidase (EC 1.9.3.2) of Pseudomonas (for a review, see Poole, 1982a), both of which lack copper.

Although the Pseudomonas system has been the subject of intensive biochemical and biophysical characterization, and intermediates in the reaction with $\mathrm{O}_{2}$ have been identified (Greenwood et al., 1978), this oxidase is somewhat atypical in being water-soluble and also having nitrite reductase activity. We are studying, therefore, the reactions between $\mathrm{O}_{2}$ and reduced cytochrome $d$ in $E$. coli, exploiting the low-temperature trapping techniques that have proved successful in identification of intermediates in the $\mathrm{O}_{2}$ reactions of the mitochondrial oxidase (Chance et al., 1975 a, b) and of cytochrome $o$ in E. coli (Poole et al., 1979b, $c$; Poole \& Chance, 1981 ; Poole, 1982 b). The results presented here extend our recent finding (Poole et al., $1982 a$ ) that reduced cytochrome $d$ recombines with CO at temperatures lower than for any other oxidase studied. At temperatures above $\sim-153^{\circ} \mathrm{C}$, photolysis of the $\mathrm{CO}$ complex is followed by ligand exchange for $\mathrm{O}_{2}$ giving a compound $\left(d_{650}\right)$ that we believe to be an early intermediate in the $\mathrm{O}_{2}$ reaction (Poole et al., 1983) and not the fully oxidized form. This paper reports on subsequent reactions of this compound and cytochrome $b$ oxidation. Parts of this work have been presented in abstract form (Poole, 1982b; Poole et al., 1982b).

\section{METHODS}

Organism, growth conditions and preparation of cells and membranes. These were exactly as described in the preceding paper (Poole et al., 1983).

Low temperature spectral studies. These were performed as described by Poole et al. (1983). Oxygen was introduced to the $\mathrm{CO}$-liganded, reduced cell suspension at -22 to $-25^{\circ} \mathrm{C}$ either by vigorously stirring with a wire (Chance et al., 1975a) or by gently mixing with the suspension a volume of the buffer (containing $30 \%, \mathrm{v} / \mathrm{v}$, ethylene glycol) that was air saturated $\left(2 \mathrm{mM}-\mathrm{O}_{2}\right.$; de Fonseka \& Chance, 1980$)$ at $-22^{\circ} \mathrm{C}$. After photolysis, the extent of absorbance changes of cytochrome $d$ in the near-infrared region was linearly dependent on oxygen concentration as adjusted by the addition of air-saturated buffer (see Results). This enabled a calibration of the stirring technique to be made: stirring for $30 \mathrm{~s}$ was found to give $410 \mu \mathrm{M}-\mathrm{O}_{2}$, a value in reasonable agreement with $360 \mu \mathrm{M}$, the value given by Chance et al. (1975a) and assumed in our previous work on the E. coli oxidases. Aeration for $30 \mathrm{~s}$ of the $\mathrm{CO}$-reduced sample at $-25^{\circ} \mathrm{C}\left(=410 \mu \mathrm{M}-\mathrm{O}_{2}\right)$ typically resulted in a 5 to $30 \%$ loss of the (reduced $+\mathrm{CO}$ ) form of cytochrome $d$ (see also Poole et al., 1983). After trapping the oxygenated sample at $-78^{\circ} \mathrm{C}$ and equilibrating at low temperatures in the dual-wavelength spectrophotometer, photolysis was achieved with the xenon lamp or laser described previously, or a more powerful $4.0 \mathrm{~mW}$ He-Ne laser (Spectra Physics, Mount View, Calif. 94042, U.S.A.). The laser beam was directed to the sample by light guides and positioned to give maximum illumination of the cuvette as judged from the photomultiplier voltage. To investigate the possibility that the multiple flashes from the xenon lamp might perturb the temperature of the sample, a thermocouple was inserted in a cell suspension in the $2 \mathrm{~mm}$ path-length cuvette at $-25^{\circ} \mathrm{C}$ and then frozen. Direct measurement of the temperature of the suspension equilibrated in the spectrophotometer at $-80^{\circ} \mathrm{C}$ showed it to be constant $\left(-80 \pm 1{ }^{\circ} \mathrm{C}\right)$ during 30 flashes of the xenon lamp over a period of $43 \mathrm{~s}$.

Physical methods. The Johnson Foundation dual-wavelength scanning spectrophotometer was used (Poole \& Chance, 1981; Poole et al., 1983). Transmitted light was monitored with an S-10 type photomultiplier for the 390 to $700 \mathrm{~nm}$ range (EMI 9592B or 9214) or an S-1 type photomultiplier (RCA 7102) for the 550 to $860 \mathrm{~nm}$ range. Reference wavelengths are given in the Figure legends. 


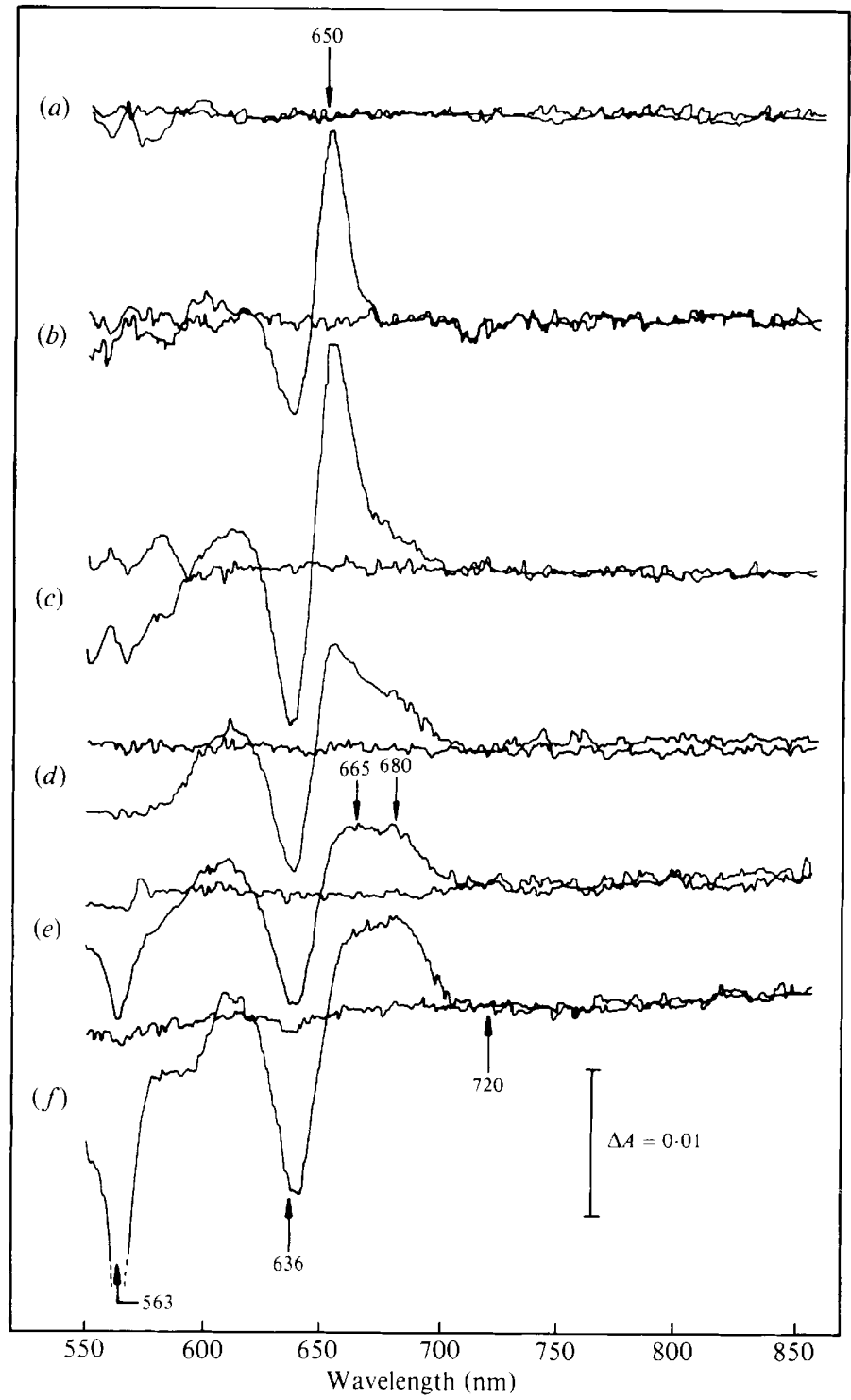

Fig. 1. Flash photolysis of $\mathrm{CO}$-liganded, reduced cells at low temperatures and observation in the 550 to $860 \mathrm{~nm}$ range. In $(a)$, the sample was freeze-trapped in the absence of $\mathrm{O}_{2}$ and its spectrum scanned and stored in the digital memory of the dual-wavelength spectrophotometer at $-132^{\circ} \mathrm{C}$. This spectrum was subtracted from a subsequent prephotolysis spectrum to yield the reduced $+\mathrm{CO}$ minus reduced $+\mathrm{CO}$ baseline, or from the spectrum recorded immediately after photolysis ( 30 flashes of a $200 \mathrm{~J}$ xenon lamp). In $(b)$ to $(f)$, the procedure was identical except that $\mathrm{O}_{2}$ (approx. $400 \mu \mathrm{M}$ ) was present and spectra were scanned at $-132^{\circ} \mathrm{C}(b),-97{ }^{\circ} \mathrm{C}(c),-88^{\circ} \mathrm{C}(d),-80^{\circ} \mathrm{C}(e)$ or $-70^{\circ} \mathrm{C}(f)$. In each case, the reference wavelength was $720 \mathrm{~nm}$ and the scan speed approx. $1.4 \mathrm{~nm} \mathrm{~s}^{-1}$. Protein concentration was $11.8 \mathrm{mg} \mathrm{ml}^{-1}$.

\section{RESULTS}

Spectra of compounds formed between cytochrome d and oxygen at sub-zero temperatures after photolysis with white light

When the CO-liganded, reduced forms of mitochondrial cytochrome oxidase (cytochrome $a a_{3}$ ) or $E$. coli cytochrome $o$ are flash photolysed in the absence of $\mathrm{O}_{2}$ at low temperatures (below about $-120^{\circ} \mathrm{C}$ ), the spectrum obtained is that of the reduced form. This arises because the 


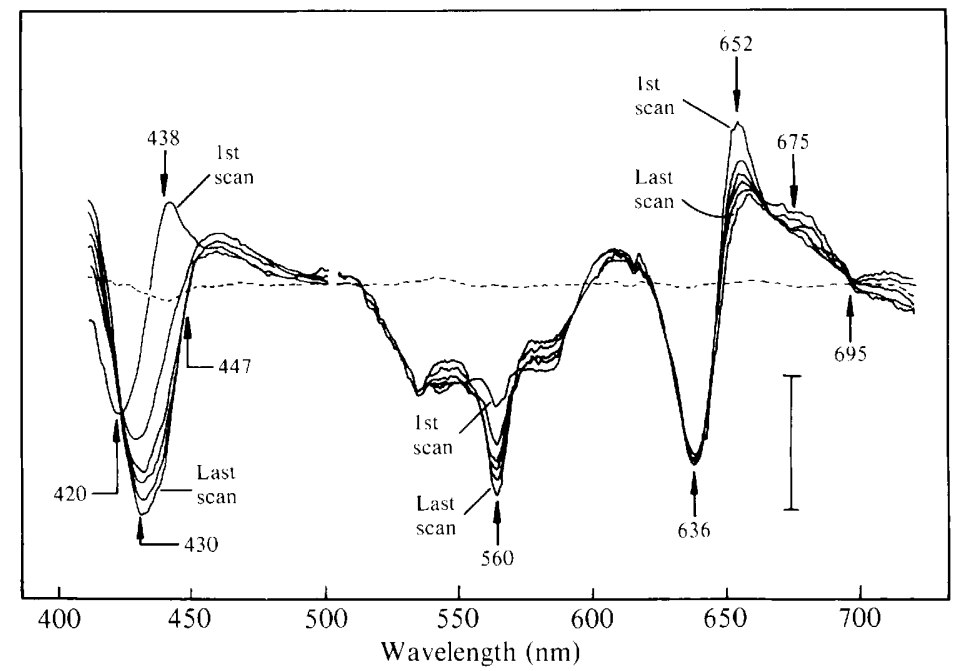

Fig. 2. Repetitive wavelength scanning of the reactions with $\mathrm{O}_{2}$ of cytochromes at $-91{ }^{\circ} \mathrm{C}$. The spectrum of a suspension of CO-liganded reduced cells was scanned and stored in the memory of the dual-wavelength spectrophotometer; the reference wavelength was $500 \mathrm{~nm}$. Subsequent scans are difference spectra with the stored spectrum subtracted. The first scan, before photolysis, yielded the baseline indicated by the dashed line. The reaction was initiated by 30 flashes of a $200 \mathrm{~J}$ lamp. Subsequent scans were initiated approx. $4 \cdot 1,8 \cdot 2,12 \cdot 3,16 \cdot 4,25 \cdot 5$ and $40.6 \mathrm{~nm}$ after the start of the baseline. The vertical bar represents $\Delta A=0.008$ above $500 \mathrm{~nm}$ and 0.016 below $500 \mathrm{~nm}$. The scan speed was approx. $1.4 \mathrm{~nm} \mathrm{~s}^{-1}$ and the protein concentration $8 \mathrm{mg} \mathrm{ml}^{-1}$. The directions of absorbance changes in successive scans are decreases at 430,438,560 and $652 \mathrm{~nm}$ and an increase at $675 \mathrm{~nm}$.

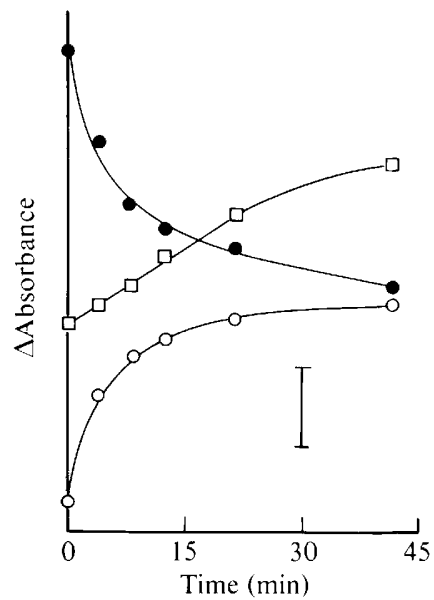

Fig. 3. Absorbance changes during the reaction with oxygen at $-91{ }^{\circ} \mathrm{C}$. The absorbance changes shown in Fig. 2 and measured at $430-447 \mathrm{~nm}(\bigcirc), 652-636 \mathrm{~nm}(\bigcirc)$ and 675-695 nm ( $\square$ ) are plotted as a function of time. The vertical bar represents $\Lambda A 0.008,0.0016$ and 0.0008 , respectively. Zero time for each plot is the moment of traversing the first wavelength of each pair in the first scan after photolysis.

recombination of $\mathrm{CO}$ with the reduced oxidase is immeasurably slow at these temperatures. However, Poole \& Chance $(1980,1981)$ showed that cytochrome $d$ behaves anomalously in similar experiments, the only features observable in the 410 to $660 \mathrm{~nm}$ region being due to cytochrome $o_{436}$. Fig. $1(a)$ confirms and extends these results, the difference spectrum (with respect to the CO-liganded form) being featureless as far as $860 \mathrm{~nm}$. The explanation (Poole $e t$ $a l ., 1982 a)$ is that reduced cytochrome $d$ binds $\mathrm{CO}$ at exceptionally low temperatures $(-269$ to $-153{ }^{\circ} \mathrm{C}$ ) so that recombination is complete within the first scan at $-132^{\circ} \mathrm{C}$. In the presence of $400 \mu \mathrm{M}-\mathrm{O}_{2}$ (Fig. 1 b) the difference spectrum shows an intense peak at 650 to $652 \mathrm{~nm}$ (attributed 
to the formation of an early intermediate, $d_{650}$; Poole et al., 1983) and a trough at $636 \mathrm{~nm}$, resulting from disappearance of the $\mathrm{CO}$-liganded form in the flash photolysis spectrum. Figs $1(c)$ to $1(f)$ show the first spectra, and their respective baselines, obtained after photolysis at successively higher temperatures. At $-97^{\circ} \mathrm{C}$ (Fig. 1 c) the major peak and trough remain but a shoulder to the $652 \mathrm{~nm}$ peak appears at 670 to $690 \mathrm{~nm}$. Further warming to $-88^{\circ} \mathrm{C}$ (Fig. $1 \mathrm{~d}$ ) or $-80^{\circ} \mathrm{C}$ (Fig. $1 e$ ) causes this shoulder to intensify with concomitant loss of the peak. The shoulder is very broad but centred at 670 to $675 \mathrm{~nm}$. At $-80^{\circ} \mathrm{C}$ and higher temperatures $\left(-70{ }^{\circ} \mathrm{C}\right.$; Fig. $\left.1 \mathrm{f}\right)$, a trough at $562 \mathrm{~nm}$ indicates oxidation of $b$-type cytochrome(s). There were no absorbance changes between 700 and $860 \mathrm{~nm}$, with respect to the CO-reduced baseline, over the temperature range studied.

The reactions of $b$ and $d$-type cytochromes are also seen when a single sample is scanned repetitively at a constant temperature. At $-91{ }^{\circ} \mathrm{C}$ (Fig. 2), photolysis with white light resulted in the simultaneous decrease in absorbance at $652 \mathrm{~nm}$ and increase at $675 \mathrm{~nm}$. In this single sample, the constancy of the $636 \mathrm{~nm}$ intensity is more clearly seen. Between 500 and $600 \mathrm{~nm}$, the $\alpha$ and $\beta$ bands of cytochrome(s) $b$ at about 530 and $560 \mathrm{~nm}$, respectively, are seen. In the Soret region, all scans but the first show a cytochrome $b$ trough at $430 \mathrm{~nm}$ which deepens concomitantly with the $\alpha$ band. Changes at 652,430 and $675 \mathrm{~nm}$ are shown in Fig. 3. Plots of the logarithm of the absorbance changes of the first two components were each bilinear, suggesting two pseudo-first-order processes for each component (results not shown). For cytochrome ' $d_{650}$ ' $(652 \mathrm{~nm})$, the faster phase persisted for approx. $10 \mathrm{~min}$ after photolysis $\left(t_{\frac{1}{2}}\right.$ approx. $30 \mathrm{~min}$ ) and was followed by a much slower phase with $t_{\frac{1}{2}}>200 \mathrm{~min}$. Similar kinetics were observed in five such experiments at this temperature. Multiphasic kinetics in haemoprotein reactions have been observed by others, particularly in ligand-binding studies (e.g. Poole et al., 1979c; Denis \& Richaud, 1982) and, although not fully understood, have been interpreted in terms of discrete energy barriers encountered by the approaching ligand (Austin et al., 1975). Although continuous recording of the absorbance change at a fixed wavelength (with respect to a fixed reference wavelength) would have provided data more suitable for detailed kinetic analysis, the purpose of the present experiment was to demonstrate the kinetic distinction between the changes at 652 and $430 \mathrm{~nm}$ compared with the almost linear increase in absorbance of the unidentified chromophore at $675 \mathrm{~nm}$. There are no distinct changes in the region between 440 and $450 \mathrm{~nm}$ (Fig. 2) where the Soret band of $a$-type cytochromes is expected. The weakness of the Soret bands of $d$-type cytochromes has been reported previously (Chance, 1953; Yamanaka \& Okunuki, 1963; Poole et al., 1981; Poole \& Chance, 1981).

\section{Reactions with ligands of cytochromes in membrane particles}

Reactions similar to those described above for intact cells were also observed in membrane particles prepared by ultrasonic disruption and differential centrifugation (Poole et al., 1983). Photolysis at $-94{ }^{\circ} \mathrm{C}$ of an anoxic sample that had been reduced with succinate and bubbled with $\mathrm{CO}$ revealed only cytochrome $o_{436}$ (results not shown). In the presence of $400 \mu \mathrm{M}-\mathrm{O}_{2}$, however, additional signals at about $635 \mathrm{~nm}$ (trough) and $652 \mathrm{~nm}$ (peak) were seen at $-94{ }^{\circ} \mathrm{C}$. Thus, the reactions attributed to both cytochrome $o_{436}$ (Poole \& Chance, 1981) and cytochrome $d$ are those of oxidases tightly bound to the cytoplasmic membrane.

\section{Reactions of cytochromes $d$ and b following photolysis with monochromatic light}

Cells from $\mathrm{O}_{2}$-limited cultures contain, in addition to cytochrome $d$, two other cytochromes whose CO-complexes may be photolysed by white light, cytochromes $a_{1}$ and $o_{436}$. Cytochrome $a_{1}$ is present at low concentrations; its small absorbance at about $595 \mathrm{~nm}$ in difference spectra, with the CO-liganded form as reference (Poole et al., 1981), does not confound the large spectral changes of cytochrome $d$ seen in $\mathrm{O}_{2}$-supplemented samples (Fig. $1 b$ to $f$; Fig. 2). In contrast, cytochrome $o_{436}$ has distinctive absorbances in the Soret, $\alpha$ and $\beta$ regions (Poole \& Chance, 1981 ) and cannot be easily distinguished from other $b$-type cytochromes that may be oxidized by cytochrome $d$ (Figs 2 and 3). Monochromatic light from a He-Ne laser $(633 \mathrm{~nm})$, however, photolyses the cytochrome $d$-CO complex, but not the $o-\mathrm{CO}$ complex (Poole \& Chance, 1981); 


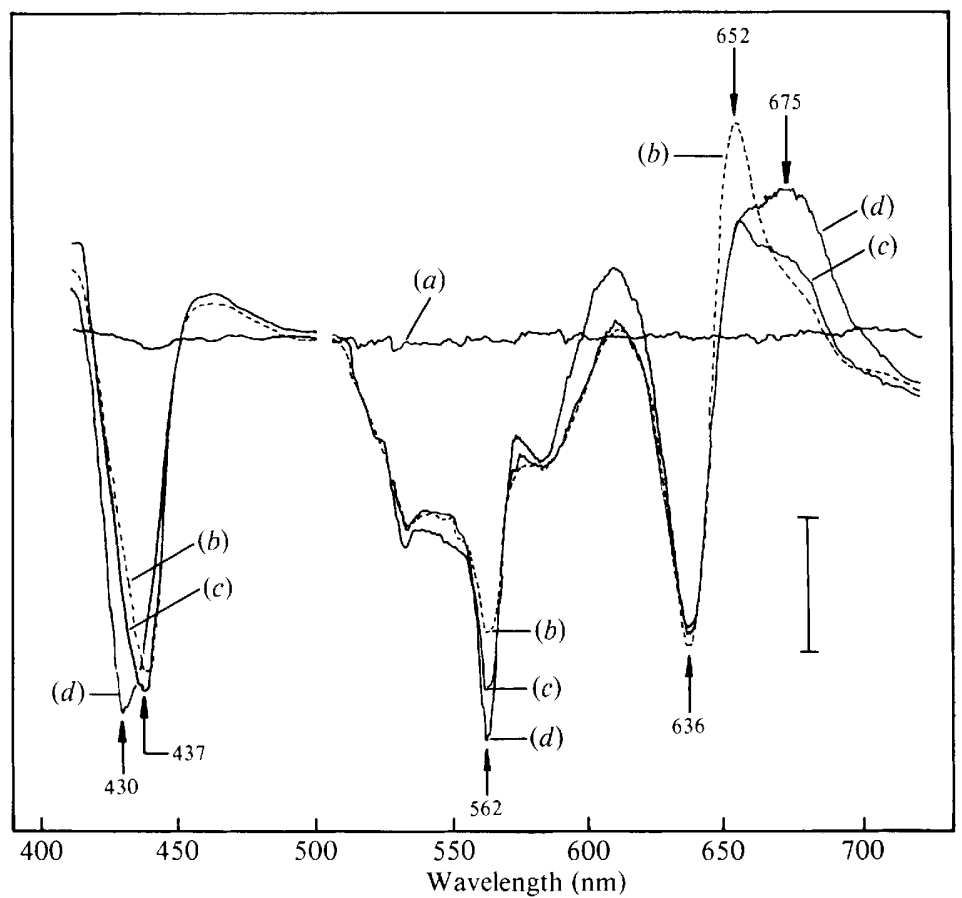

Fig. 4. Oxidation of cytochrome $b$ during the $\mathrm{O}_{2}$ reaction. The spectrum of a CO-liganded, reduced cell suspension was scanned at $-81{ }^{\circ} \mathrm{C}$ and stored in the memory of the dual-wavelength spectrophotometer (reference wavelength $500 \mathrm{~nm}$ ) and subtracted from subsequent spectra. The CO-reduced minus $\mathrm{CO}$-reduced baseline is shown by $(a)$. Photolysis was by $10 \mathrm{~min}$ exposure to the beam of a $4 \mathrm{~mW} \mathrm{He}-\mathrm{Ne}$ laser and followed immediately by a further scan $(b$; dashed line) and another after $16 \mathrm{~min}(c)$. The sample temperature was then raised to $-70^{\circ} \mathrm{C}$, returned to $-81^{\circ} \mathrm{C}$ (results not shown) and recycled again, holding the temperature at $-70^{\circ} \mathrm{C}$ for $5 \mathrm{~min}$. Spectrum $(d)$ is that of the twice-recycled sample minus the reduced $+C O$ reference spectrum. The vertical bar represents $\Delta A=0 \cdot 016$ above $500 \mathrm{~nm}$ and 0.04 below $500 \mathrm{~nm}$. The scan speed was approx. $2.8 \mathrm{~nm} \mathrm{~min} \mathrm{~m}^{-1}$ and the protein concentration $11.5 \mathrm{mg} \mathrm{ml}^{-1}$.

thus, further evidence for oxidation of $b$-type cytochromes is afforded by Fig. 4. The first scan after laser photolysis at $-81^{\circ} \mathrm{C}$ is characterized by the $652 \mathrm{~nm}$ peak, a small shoulder at $675 \mathrm{~nm}$ and a trough at $437 \mathrm{~nm}$. Repetitive scanning of the sample over $20 \mathrm{~min}$ (results not shown) revealed changes in the signals similar to those seen after photolysis with white light (Fig. 2). After transient warming of the sample (by disconnecting the flow of cooled $\mathrm{N}_{2}$ to the cuvette), the troughs at 437 and $562 \mathrm{~nm}$ deepen. After warming, the temperature was returned to $-81^{\circ} \mathrm{C}$, the temperature at which the reference spectrum was scanned, to obviate optical artefacts arising from light scattering and devitrification. A further warming cycle intensified the $675 \mathrm{~nm}$ component, deepened the $562 \mathrm{~nm}$ trough and shifted the Soret trough by $7 \mathrm{~nm}$ to $430 \mathrm{~nm}$. This indicates successive oxidation of at least two cytochromes $b$. That the $437 \mathrm{~nm}$ component observed after laser photolysis in the presence of $\mathrm{O}_{2}$ is not cytochrome $o_{436}$ was confirmed by comparing directly the spectra of forms obtained in the presence and absence of $\mathrm{O}_{2}$. Thus at $-100{ }^{\circ} \mathrm{C}$, with $400 \mu \mathrm{M}-\mathrm{O}_{2}$ present, photolysis with the $\mathrm{He}-\mathrm{Ne}$ laser gave the near-infrared signals of cytochrome $d$ plus a prominent trough at $437 \mathrm{~nm}$ similar to that seen at $-81{ }^{\circ} \mathrm{C}$ (Fig. 4). Further irradiation of the sample with 30 flashes from a xenon lamp resulted in a broad Soret peak (maximum $439 \mathrm{~nm}$ ) that is probably the sum of the intense peak of cytochrome $o_{436}$ (Poole $\&$ Chance, 1981) and the trough extant prior to the xenon flashes (results not shown). In contrast, a repeat of the experiment with an anoxic suspension gave a featureless spectrum after laser photolysis (not shown) and the spectrum of cytochrome $o_{436}$ after xenon flashing (see Fig. $2 b$ of Poole \& Chance, 1981). These experiments show that the cytochrome $o_{436}-\mathrm{CO}$ complex is 


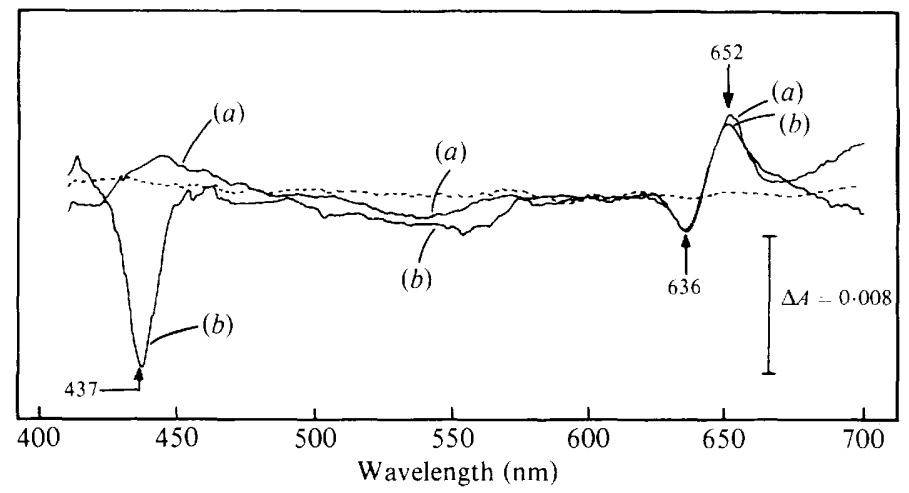

Fig. 5. Appearance of $b$ and $d$-type cytochromes following photolysis with monochromatic light. The spectrum of a CO-liganded, reduced cell suspension was scanned and stored in the memory of the dualwavelength spectrophotometer at $-131^{\circ} \mathrm{C}$ (reference wavelength $500 \mathrm{~nm}$ ). Subtraction of this from the subsequent scan of the unphotolysed sample gave the reduced $+\mathrm{CO}$ minus reduced $+\mathrm{CO}$ baseline (dashed line). The sample was exposed for $10 \mathrm{~min}$ to the beam of a $0.95 \mathrm{~mW}$ laser and the spectrum recorded $(a)$ using the stored spectrum as reference. The sample was then warmed to $-90{ }^{\circ} \mathrm{C}$ and returned to $-131{ }^{\circ} \mathrm{C}$ where a further difference spectrum $(b)$ was recorded. The scan speed was approx. $1.4 \mathrm{~nm} \mathrm{~s}^{-1}$ and the protein concentration $8 \mathrm{mg} \mathrm{ml}^{-1}$.

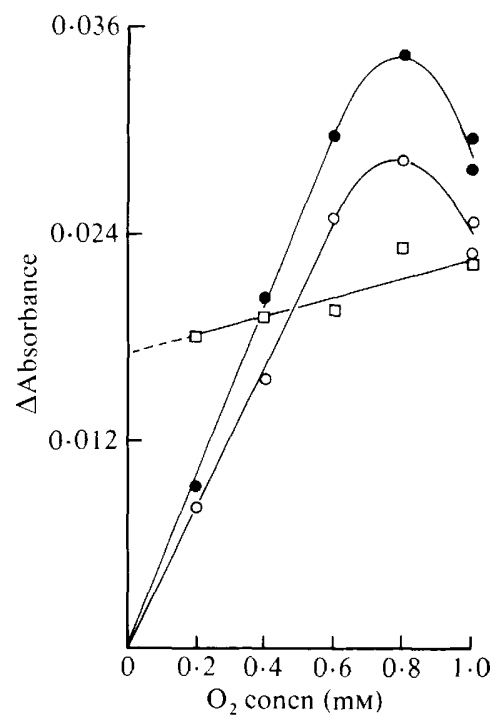

Fig. 6. Dependence of the intensities of bands due to cytochromes $o_{436}$ and $d$ on $\mathrm{O}_{2}$ concentration in the sample. Each CO-liganded, reduced cell suspension, to which the indicated concentration of oxygen had been added at $-25^{\circ} \mathrm{C}$, was scanned and stored in the dual-wavelength spectrophotometer and subtracted from subsequent scans of the same sample. Photolysis was achieved by 10 min exposure to a $4 \mathrm{~mW} \mathrm{He}-\mathrm{Ne}$ laser $(\mathrm{O})$, and was followed in $(\bigcirc)$ and $(\square)$ with 10 flashes from a $200 \mathrm{~J}$ xenon lamp. The wavelength pairs measured are 652 minus $636 \mathrm{~nm}(\mathrm{O}, \bigcirc)$ and 436 minus $415 \mathrm{~nm}(\square)$. The temperature was $-132^{\circ} \mathrm{C}$, the scan range 410 to $720 \mathrm{~nm}$, the reference wavelength $500 \mathrm{~nm}$, and the scan speed approx. $1.4 \mathrm{~nm} \mathrm{~s}^{-1}$. The protein concentration was $14.6 \mathrm{mg} \mathrm{ml}^{-1}$.

photolysed by white light in the absence or presence of $\mathrm{O}_{2}$ and that a trough observed following laser photolysis in the presence of $\mathrm{O}_{2}$ at the same temperature is due instead to another $b$-type cytochrome.

Cytochrome $b$ oxidation is a consequence of the reaction of cytochrome $d$ with $\mathrm{O}_{2}$. Laser photolysis of the oxidase at $-131^{\circ} \mathrm{C}$ (Fig. 5) gives rise to the same spectral changes in the nearinfrared as those seen after photolysis with white light (Fig. 1b). As shown previously (Poole \& 
Chance, 1981) the Soret changes are small when only cytochrome $d$ is photolysed. However, warming the sample to $-90^{\circ} \mathrm{C}$ and recycling to $-131^{\circ} \mathrm{C}$ results in the oxidation of a $b$-type cytochrome seen at $437 \mathrm{~nm}$.

\section{Effect of oxygen concentration on the reactions of cytochrome d}

The concentration of dissolved $\mathrm{O}_{2}$ at the time of freeze-trapping was varied by gently mixing $\mathrm{O}_{2}$-saturated buffer with the $\mathrm{CO}$-saturated cell suspension at $-25^{\circ} \mathrm{C}$. Photolysis of the sample at $-132{ }^{\circ} \mathrm{C}$ resulted in the appearance of cytochrome $d$ signals, whose magnitude was linearly proportional to oxygen concentration, up to $0.6 \mathrm{~mm}-\mathrm{O}_{2}$ (Fig. 6). In the Soret region, a broad band at 440 to $450 \mathrm{~nm}$ of low intensity was observed, as shown in Fig. 5. At higher $\mathrm{O}_{2}$ concentrations, the intensity of the $d$ signals declined, probably due to displacement of $\mathrm{CO}$ from the oxidase and consequent $\mathrm{O}_{2}$ binding. Irradiation with white light following each laser experiment gave approximately $15 \%$ enhancement of the $d$ signals, but also elicited the appearance of cytochrome $o_{436}$ in the Soret region. The intensity of the latter signal was relatively independent of $\mathrm{O}_{2}$ concentration; the slight increase is presumably due to the influence of the increasing intensity of the broad Soret band of cytochrome $d$.

\section{DISCUSSION}

The remarkable functional properties of cytochrome $d$ in $E$. coli are its ability to bind $\mathrm{CO}$ at temperatures between $\sim-269$ and $-153^{\circ} \mathrm{C}$ (Poole et al., 1982a) and the rapid ligand exchange that occurs when the CO-liganded form is photolysed in the presence of $\mathrm{O}_{2}$ at higher temperatures (Poole et al., 1983; this paper). Both these features are unique amongst cytochrome oxidases studied to date. An explanation of these phenomena in terms of the enzyme's composition and structure cannot be given at present. This oxidase has proved particularly refractory to purification, but studies of the solubilized and partially purified respiratory oxidase complex (Reid \& Ingledew, 1980) have suggested the presence of two spectrally and potentiometrically different $b$-type cytochromes, and two haems $d$. Such a configuration is closely analogous to the cytochrome oxidase of Pseudomonas aeruginosa (Kuronen \& Ellfolk, 1972). This enzyme contains two haems $c$ and two haems $d_{1}$, the latter being the binding site(s) for CO, cyanide and $\mathrm{O}_{2}$ (Parr et al., 1975; Greenwood et al., 1978). It also exhibits rapid CO rebinding after photolysis at temperatures close to that of liquid He (Sivaram et al., 1982). However, in marked contrast to the $E$. coli cytochrome $d$-containing oxidase, this enzyme is membrane-attached but water-soluble.

\section{The function of copper}

In the reaction of the mitochondrial cytochrome $c$ oxidase with oxygen, the reactive centre consists of the coupled metal pair cytochrome $a_{3}$ and its associated copper $\left(\mathrm{Cu}_{a_{3}}\right)$, whereas cytochrome $a$ and $\mathrm{Cu}_{a}$ serve an electron 'reservoir' or 'ballast' function (Chance, 1981), donating electrons to the bound peroxide intermediate in $\mathrm{O}_{2}$ reduction. The only band in the visible spectrum of the enzyme attributable to copper is a weak absorption at 830 to $840 \mathrm{~nm}$ (for references, see Beinert et al., 1980). There is no convincing evidence for the role of copper in the respiratory chain of $E$. coli. An EPR investigation by Lund \& Raynor (1975) of membrane particles from nine bacterial species, including $E$. coli, failed to show a $\mathrm{Cu}^{2+}$ signal in either oxidized or reduced forms at $77 \mathrm{~K}$.

The present study shows that if copper is present in the cytochrome $d$ of $E$. coli, its environment must be quite different from that in mitochondrial cytochrome oxidase, since no significant absorbance between 720 and $860 \mathrm{~nm}$ was detectable over a wide temperature range, where all oxidation states of the oxidase are thought to be represented. Since these cells also contain cytochrome $o_{436}$ (Poole \& Chance, 1981), it is inferred that this oxidase too lacks copper in the form found in the mitochondrial enzyme. 
The unidentified chromophore at 670 to $680 \mathrm{~nm}$

Analysis of the absolute absorption spectrum of cytochrome $d$ in Azotobacter vinelandii (in a state described as oxidized, although no details of sample preparation were given) has revealed three Gaussian components (Kauffman \& van Gelder, 1973a). The peak positions (with band widths) were $635(34), 648(21)$ and $670(38) \mathrm{nm}$. On exhaustion of oxygen, the $648 \mathrm{~nm}$ band decreased before the $670 \mathrm{~nm}$ component. The latter was also diminished by reduction in the presence of cyanide (Kauffman \& van Gelder, 1973 b) but was unaffected by CO (Kauffman et al., 1980). A similar absorption band $(675$ to $680 \mathrm{~nm}$ ) has also been described in $E$. coli (Pudek \& Bragg, 1974; Hendler \& Shrager, 1979) but not identified. In Thiobacillus denitrificans, intense bands at 675 to $680 \mathrm{~nm}$ were seen in reduced minus oxidized preparations when the reductant was $\mathrm{Na}_{2} \mathrm{~S}$ or in $\mathrm{CO}$ difference spectra, and were attributed to cytochrome $d$ (Aminuddin \& Nicholas, 1974). In the present paper, the appearance of a broad absorbance centred at about 675 to $680 \mathrm{~nm}$ is clearly seen when a CO liganded sample is photolysed at $-91{ }^{\circ} \mathrm{C}$ (Fig. 2) or in the first scan after photolysis at higher temperatures (Fig. 1). Although its formation is coincident with the loss of the $650 \mathrm{~nm}$ compound and cytochrome $b$ oxidation (Fig. 2), the kinetics of its formation are quite distinct (Fig. 3) and there is no clear isosbestic point between 650 and $680 \mathrm{~nm}$ during these transitions. Both observations suggest that the 650 and $680 \mathrm{~nm}$ components are only indirectly related. The haematin $d$ from $P$. aeruginosa cytochrome oxidase has an absorption maximum at $684 \mathrm{~nm}$ (Yamanaka \& Okunuki, 1963) but would not be expected to be functional in the reaction with oxygen.

\section{Reductants of cytochrome $d$}

'Although coordinate synthesis of cytochromes $b_{558}$ and $d$ is observed under a variety of apparently unrelated growth conditions, the obligatory reduction of cytochrome $d$ by cytochrome $b_{558}$ has yet to be established' (Haddock \& Jones, 1977). Laser photolysis of the COliganded cytochrome $d$ (which does not activate the reaction with oxygen of cytochrome $o_{436}$ ) and formation of cytochrome $d_{650}$ is followed by reduction of at least two $b$-type cytochromes that can be distinguished by their Soret absorption bands. Neither of the $b$-types is cytochrome $o$ (which is still liganded to $\mathrm{CO}$ under these conditions), so that evidence is obtained here for two partially independent routes of electron transfer to oxygen:

$$
\begin{aligned}
b_{437} & \rightarrow b_{430} \rightarrow d \quad \rightarrow \mathrm{O}_{2} \\
& \rightarrow\left(b_{428} ?\right) \rightarrow o_{436} \rightarrow \mathrm{O}_{2}
\end{aligned}
$$

The immediate reductant of cytochrome $o_{436}$ under these conditions has not been identified by selectively photolysing the $o_{436}-\mathrm{CO}$ complex but, in aerobically-grown cells, where the contribution of cytochrome $d$-mediated electron transfer is undetectable (Poole et al., 1979b), cytochrome $o_{432}$ appears to be oxidized by a $b$-type cytochrome with a Soret absorbance maximum at $428 \mathrm{~nm}$. The point of divergence of electron flow from a pool of quinones or $b$-type cytochromes remains to be identified. In the $d_{1}$-containing oxidase of $P$. aeruginosa, the electron donors to cytochrome $d_{1}$ are $c$-type cytochromes (Wharton \& Gibson, 1976) whilst in $A$. vinelandii a cytochrome $b \rightarrow d$ branch apparently resembles that of $E$. coli (see Haddock \& Jones, 1977).

\section{Intermediates in the reaction with oxygen}

The hypothesis that cytochrome $d_{650}$ is an early intermediate in the reaction of reduced cytochrome $d$ with oxygen is advanced in the accompanying paper (Poole et al., 1983). The present results, and Fig. 1 of Poole \& Chance (1980), support this idea by showing that the reactions following the formation of the $650 \mathrm{~nm}$ absorbing form result in a spectrum whose only distinctive feature in the near-infrared region is a trough at $636 \mathrm{~nm}$, attributable to the disappearance from the difference spectrum of the CO-liganded form. We propose that the product of the reaction is the fully oxidized enzyme, which has no distinctive spectrum in this region. The alternative explanation of the current data is that the $650 \mathrm{~nm}$ form, the immediate product of the reaction with $\mathrm{O}_{2}$, is the fully oxidized enzyme. If this were the case, subsequent electron transfer from $b$-type cytochromes would be expected to re-form the reduced oxidase. 
Since the spectrum of the latter (recorded with reference to the $\mathrm{CO}+$ reduced form) is characterized by an intense band at $628 \mathrm{~nm}$ and a trough shifted to $644 \mathrm{~nm}$ (Fig. 1 of Poole et al., 1983), and this form is not seen in the present study, we do not favour this explanation.

Further characterization of the 'invisible' and $d_{650}$ forms is required to establish the valence states of the individual redox centres, whilst more detailed kinetic studies may reveal the basis for the proposed stability of intermediates in the reaction with $\mathrm{O}_{2}$ of cytochrome $d$.

R.K.P. thanks the S.E.R.C. for financial support (GR/B/8503.6), the Wellcome Trust for a Travel Grant and the Nuffield Foundation for a Science Research Fellowship. We thank A. Sivaram and C. Kumar for valuable discussions.

\section{REFERENCES}

Aminuddin, M. \& Nicholas, D. J. D. (1974). Electron transfer during sulphide and sulphite oxidation in Thiobacillus denitrificans. Journal of General Microbiology 82, 115-123.

Austin, R. H., Beeson, K. W., Eisenstein, L., Frauenfelder, H. \& Gunsalus, I. C. (1975). Dynamics of ligand binding to myoglobin. Biochemistry 14, 5355-5373.

BARRETT, J. (1956). The prosthetic group of cytochrome $a_{2}$. Biochemical Journal 64, 626-639.

Beinert, H., Shaw, R. W., Hansen, R. E. \& Hartzell, C. R. (1980). Studies on the origin of the near-infrared $(800-900 \mathrm{~nm})$ absorption of cytochrome $c$ oxidase. Biochimica et biophysica acta $\mathbf{5 9 1}$, 458-470.

Castor, L. N. \& Chance, B. (1959). Photochemical determinations of the oxidases of bacteria. Journal of Biological Chemistry 234, 1587-1592.

Chance, B. (1953). The carbon monoxide compounds of the cytochrome oxidases. I. Difference spectra. Journal of Biological Chemistry 202, 383-396.

Chance, B. (1981). The cycling of oxygen through intermediates in the cytochrome oxidase-oxyzen reaction. In Current Topics in Cellular Regulation, vol. 18, pp. 343-360. Edited by R. W. Estabrook \& P. Srere. New York \& London: Academic Press.

Chance, B., Graham, N. \& Legallais, V. (1975a). Low temperature trapping method for cytochrome oxidase oxygen intermediates. Analytical Biochemistry 67, 552-579.

Chance, B., Saronio, C. \& Leigh, J. S. (1975b). Functional intermediates in the reaction of membranebound cytochrome oxidase with oxygen. Journal of Biological Chemistry 250, 9226-9237.

DENIS, M. \& Richaud, P. (1982). Dynamics of carbon monoxide recombination to fully reduced cytochrome $c$ oxidase in plant mitochondria after low temperature flash photolysis. Biochemical Journal 206, 379-385.

DE Fonseka, K. \& Chance, B. (1980). Oxygen kinetics of frozen cytochrome oxidase. The capacity of the oxygen pocket. Biochemical Journal 185, 527-530.

Greenwood, C., Barber, D., Parr, S. R., ANToNiNi, E., BRunori, M. \& Colosimo, A. (1978). The reaction of Pseudomonas aeruginosa cytochrome c551 oxidase with oxygen. Biochemical Journal 173, $11-17$.

HadDOCK, B. A. \& Jones, C. W. (1977). Bacterial respiration. Bacteriological Reviews 41, 47-99.

Hendler, R. W. \& Shrager, R. I. (1979). Potentiometric analysis of Escherichia coli cytochromes in the optical absorbance range of $500 \mathrm{~nm}$ to $700 \mathrm{~nm}$. Journal of Biological Chemistry 254, 1128811299.

Hoffman, P. S., Irwin, R. M., Carreira, L. A., Morgan, T. V., Ensley, B. D. \& Dervartanian, D. V. (1980). Studies of photochemical action spectra on $N^{\prime}, N^{\prime}, N^{\prime}, N^{\prime}$-tetramethyl-p-phenylenediamine-oxidase-negative mutants of Azotobacter vinelandii. European Journal of Biochemistry 105, 177185.

JoNES, C. W. (1978). Microbial oxidative phosphorylation. Biochemical Society Transactions 6, 361-363.

Kauffman, H. F. \& Van Gelder, B. F. (1973a). The respiratory chain of Azotobacter vinelandii. I. Spectral properties of cytochrome d. Biochimica et biophysica acta 305, 260-267.

Kauffman, H. F. \& van Gelder, B. F. (1973b). The respiratory chain of Azotobacter vinelandii. II. The effect of cyanide on cytochrome $d$. Biochimica et biophysica acta 314, 276-283.

Kauffman, H. F., van Gelder, B. F. \& DervartanIAN, D. V. (1980). Effect of ligands on cytochrome $d$ from Azotobacter vinelandii. Journal of Bioenergetics and Biomembranes 12, 265-276.

KeILIN, D. (1933). Supposed direct spectroscopic observation of the "oxygen-transporting ferment". Nature, London 132, 783.

Kuronen, T. \& Ellfolk, N. (1972). A new purification procedure and molecular properties of Pseudomonas cytochrome oxidase. Biochimica et biophysica acta 275, 308-318.

LEMBERG, R. \& BARRETT, J. (1973). Bacterial cytochromes and cytochrome oxidases. In Cytochromes, pp. 217-236. London \& New York: Academic Press.

LudwiG, B. (1980). Heme $a a_{3}$-type cytochrome $c$ oxidases from bacteria. Biochimica et biophysica acta 594, 177-189.

LUND, T. \& RAYNoR, J. B. (1975). Electron spin resonance of some bacterial respiratory membranes. Bioenergetics 7, 161-166.

Parr, S. R., Wilson, M. T. \& Greenwood, C. (1975). The reaction of Pseudomonas aeruginosa cytochrome $c$ oxidase with carbon monoxide. Biochemical Journal 151, 51-59

PoOLE, R. K. (1982a). The oxygen reactions of bacterial cytochrome oxidases. Trends in Biochemical Sciences 7, 32-34.

Poole, R. K. (1982b). The reactions of terminal oxidases in Escherichia coli $\mathrm{K} 12$ with oxygen and carbon monoxide at sub-zero temperatures. Biochemical Society Transactions 10, 485-488. 
Poole, R. K. \& Chance, B. (1980). Intermediates in the reaction with oxygen of cytochrome $d$ in oxygenlimited Escherichia coli. First European Bioenergetics Conference Short Reports, pp. 107-108. Bologna: Pàtron Editore.

Poole, R. K. \& Chance, B. (1981). The reaction of cytochrome $o$ in Escherichia coli $\mathrm{K} 12$ with oxygen. Evidence for a spectrally and kinetically distinct cytochrome $o$ in cells from oxygen-limited cultures. Journal of General Microbiology 126, 277--287.

Poole, R. K., Lloyd, D. \& Chance, B. (1979a). The reaction of cytochrome oxidase with oxygen in the fission yeast Schizosaccharomyces pombe $972 \mathrm{~h}^{-}$. Biochemical Journal 184, 555-563.

Poole, R. K., Waring, A. J. \& Chance, B. (1979b). Evidence for a functional oxygen-bound intermediate in the reaction of Escherichia coli cytochrome $o$ with oxygen. FEBS Letters 101, 56-58.

Poole, R. K., Waring, A. J. \& Chance, B. (1979c). The reaction of cytochrome $o$ in Escherichia coli with oxygen. Low temperature kinetic and spectral studies. Biochemical Journal 184, 379-389.

Poole, R. K., Scott, R. I. \& Chance, B. (1981). The light-reversible binding of carbon monoxide to cytochrome $a_{1}$ in Escherichia coli K12. Journal of General Microbiology 125, 431-438.

Poole, R. K., Sivaram, A., Salmon, I. \& Chance, B. $(1982 a)$. Photolysis at very low temperatures of COliganded cytochrome oxidase (cytochrome $d$ ) in oxygen-limited Escherichia coli. FEBS Letters 141, $237-241$.

Poole, R. K., Salmon, I., Sivaram, A., Kumar, C. \& Chance, B. (1982b). Ligand binding to cytochrome oxidase (cytochrome $d$ ) in Escherichia coli: low temperature optical and e.p.r. studies. Second European Bioenergetics Conference Short Reports, pp. 145-146. Villeurbanne: L.B.T.M.-C.N.R.S. éditeur.

Poole, R. K., Salmon, I., Kumar, C. \& Chance, B. (1983). The $650 \mathrm{~nm}$ chromophore in Escherichia coli is an 'oxy-' or oxygenated compound, not the oxidized form of cytochrome oxidase $d$ : an hypothesis. Journal of General Microbiology 129, 1335-1344.

Pudek, M. R. \& BragG, P. D. (1974). Inhibition by cyanide of the respiratory chain oxidases of Escherichia coli. Archives of Biochemistry and Biophysics 164, 682-693.

ReID, G. A. \& Ingledew, W. J. (1980). The purification of a respiratory oxidase complex from Escherichia coli. FEBS Letters 109, 1-4.

Rice, C. W. \& Hempfling, W. P. (1978). Oxygenlimited continuous culture and respiratory energy conservation in Escherichia coli. Journal of Bacteriology 134, 115-124.

Sivaram, A., Chance, B. \& Ching, Y. (1982). Low temperature photolysis and recombination kinetics of cytochrome $d$ in Pseudomonas cytochrome oxidase. Federation Proceedings 41, 1208.

Wharton, D. C. \& Gibson, Q. H. (1976). Cytochrome oxidase from Pseudomonas aeruginosa. IV. Reaction with oxygen and carbon monoxide. Biochimica et biophysica acta 430, 445-453.

Wikström, M., Krab, K. \& Saraste, M. (1981). Cytochrome Oxidase: A Synthesis, pp. 117-141. London: Academic Press.

YamanaKa, T. \& OKunuki, K. (1963). Crystalline Pseudomonas cytochrome oxidase. III. Properties of the prosthetic groups. Biochimica et biophysica acta 67, 407-416.

YAOI, H. \& TAMIYA, H. (1928). On the respiratory pigment, cytochrome, in bacteria. Proceedings of the Imperial Academy (Japan) 4, 436-439. 